\title{
Proinflammatory Status, Genetics and Atherosclerosis
}

\author{
R. POLEDNE ${ }^{1,2}$, A. LORENZOVÁA ${ }^{1,2}$, P. STÁVEK ${ }^{1,2}$, Z. VALENTA $^{3}$, J. HUBÁČEK ${ }^{1,2}$, \\ P. SUCHÁNEK ${ }^{1,2}$, J. PIŤHA ${ }^{1,2}$
}

${ }^{1}$ Center for Cardiovascular Research, ${ }^{2}$ Institute of Clinical and Experimental Medicine, ${ }^{3}$ Institute of Computer Science AS CR, v.v.i, Center for Biomedical Informatics, Prague, Czech Republic

Received June 30, 2009

Accepted October 30, 2009

\section{Summary}

Over the last decade, C-reactive protein concentration analyzed by the high sensitivity method (hSCRP) has been proven as a marker of premature atherosclerosis. Concentration exceeding $2 \mathrm{mg} / \mathrm{l}$ represents an increased individual risk of myocardial infarction and stroke but strict application of this borderline is complicated by relations of CRP concentrations to other risk factors of cardiovascular diseases. In a large $1 \%$ representative sample of the Czech population, a positive relation of hsCRP to BMI, a waist circumference and triglyceride concentration was documented. Substantial sex differences were found in its relationship to age. Whereas it is continuously increasing in men, this increase appears in women only after menopause. A substantial decrease of body weight and visceral fat volume by increased physical activity is accompanied by significant decrease of hsCRP in young obese women. This decrease was not related to a change of interleukin- 6 concentration, although it is supposed to regulate CRP production. CRP concentration is partly under genetic control as a higher concentration in young siblings of probands with proved coronary atherosclerosis was documented. The participation of genes related to lipoprotein metabolism (genes for apolipoprotein CI and apolipoprotein E) influence hsCRP concentrations. We hypothesized that an increased concentration of hsCRP represents a certain marker of proinflammatory status related to central obesity and triglyceride metabolism and it might be related to individual properties of monocytes in atherogenesis.

\section{Key words}

Atherosclerosis • Inflammation • C-reactive protein • Genetics

\section{Corresponding author}

R. Poledne, Institute for Clinical and Experimental Medicine, Videnska 1958/9, 14021 Prague 4, Czech Republic. E-mail: rudolf.poledne@ikem.cz

\section{Introduction}

During second half of the last century, the incrustation hypothesis of atherosclerosis dominated the fields of epidemiology, pathophysiology, human physiology and clinical studies related to cardiovascular diseases (CVD). A high concentration of circulating cholesterol in blood was documented as the casual reason of increasing CVD deaths in both industrialized and developing countries (Keys 1952, Keys 1970). The high concentration of total plasma cholesterol was defined as the most important risk factor due to a high saturated fat diet that potentiated atherosclerosis development and early coronary or stroke death. During this period, the original inflammation hypothesis of atherosclerosis as described in the second half of the $19^{\text {th }}$ century by Wirchow had been put to the back burner and the majority of research was concentrated on the lipoprotein metabolism, adverse effect of oxidized LDL and the protective effect of high density lipoprotein particles in atherogenesis (Castelli et al. 1986).

Wirchow's hypothesis was rediscovered by Russell Ross in 1990s with the formulation "response to injury" hypothesis (for review see Ross 1999) which proposed that endothelial denudation is the first step of atherogenesis followed by monocytes and T-cells infiltration to arterial wall (Jonasson et al. 1986, van der Wal et al. 1989). Infectious diseases and high homocysteine concentration were supposed to play a starting role in endothelial injury (Saikku et al. 1988). Although these two starting effects have been neglected by more recent results (Ridker et al. 1999b), endothelial dysfunction induced by numerous effects must be 
included in the pathophysiology of atherogenesis. Accelerated adhesion of monocytes and T-cells on the surface of arterial wall (Springer and Cybulsky 1996) which consequently invade the subendothelial space and gradually develop into macrophages represent the starting points of atherogenesis. At this point, the two opposing hypotheses, the incrustation and inflammation combine together Stehbens (1999). Monocytes invading the arterial wall play a crucial role in the cleaning of subendothelial space from abundant LDL particles which are more frequently presented within the arterial wall due to the substantial increase of their intravasal concentration. Receptor mediated pathway for cholesterol homeostasis in macrophages (Brown and Goldstein 1986) represents a simple but accommodating link between the incrustation and inflammation hypotheses of atherosclerosis. Although increased concentration of LDL particles is required for atherogenesis, the central role of this process is played by monocytes and macrophages. The pathophysiology of atherosclerosis required both - an increased presence of LDL particles within arterial wall (accelerated inflow of cholesterol to furnish smooth muscle cells for structure of their membranes) and also the presence of monocytes developing gradually to macrophages. These macrophages play not only starting role of the process but play an important role in the vulnerability or stability of the already existing atherosclerosis plaque and their increased activity represents certain proinflammatory status. More than 10 years ago, a marker of individual risk of this proinflammatory status predisposing for accelerated atherosclerosis and an increased risk of cardiovascular death had been described (Ridker et al. 1998).

\section{C-reactive protein as a marker of CVD risk and proinflammatory status}

C-reactive protein (CRP) is a protein of acute phase produced in the liver as a result of increased interleukin-6 (Il-6) stimulation of its synthesis. Macrophages are supposed to produce more Il-6 after different type of injury (infection, injury, etc.). Although relation of slightly increased CRP concentration was mentioned first by Mendall et al. (1996), the most important data were presented by Ridker et al. (1997). Numerous results have been published since this time documenting the relationship of hsCRP to CVD risk. The increased risk of CVD was identified in the range of concentration under a usual limit of pathology status (usually $10 \mathrm{mg} / \mathrm{l}$ ). To analyze CRP concentration under this limit (in the "normal" range) requires the use a special type of kits with high sensitivity and these concentrations are described as hsCRP. Using this method, CRP concentration in "the normal range" was shown to be a very stable parameter in individuals (Ridker et al. 1999a).

During last 10 years, it has been agreed that individuals with CRP concentration under $1 \mathrm{mg} / \mathrm{l}$ are in low risk of CVD whereas those with concentration over $3 \mathrm{mg} / \mathrm{l}$ are in high risk with medium risk between 1 and 3 . The importance of CRP as a marker of individual risk of CVD was amplified recently by a prospective study with administration of statins to individuals with normal concentration of LDL cholesterol (Ridker et al. 2008). Statins were able to a prevent significant amount of deaths in individuals with normal LDL cholesterol concentration but with increased CRP concentration, as they decrease of CRP concentration directly.

\section{CRP and similar CVD risk markers}

CRP concentration is related to other risk factors of CVD The importance of CRP concentration in the individual risk of CVD assessment is complicated by its relationship to numerous traditional CVD risk factors. This relationship has been published in different sets of individuals repeatedly (for review see Dvoŕáková and Poledne 2004). When we analyzed hsCRP concentration in a large representative sample of the Czech population of age between 25-65 (Czech MONICA), a highly significant relationship to other variables were obtained. CRP concentration is related positively to body weight both in men and women (Fig. 1). It was also related to the fasting concentration of triglycerides but no correlation to LDL or total cholesterol was found (data not shown). It might be concluded that concentration of CRP is a marker of metabolic syndrome as it is related to insulin resistance (Yudkin et al. 1999, Festa et al. 2000). We also documented that CRP concentration is directly related to the volume of visceral fat determined by magnetic resonance (Tintěra et al. 2004). CRP was also higher in smokers compared to non-smokers (1.39 \pm 0.82 and $1.83 \pm 1.03 \mathrm{mg} / \mathrm{l}, \mathrm{p}<0.01)$. Interestingly, the relationship of CRP to age was different in both sexes (Fig. 1). Whereas in men it is continuously increasing with age from 25 to $65 \mathrm{yrs}$, this increase is manifested in women only after menopause and is flat in reproductive period. These two phases of proinflammatory status in women (contrary to 
men) in ontogeny might play a role in lower CVD mortality in women during the reproductive period followed by much steeper increase (compared to men) of CRP concentration corresponding to increased mortality after menopause.

\section{CRP and age}
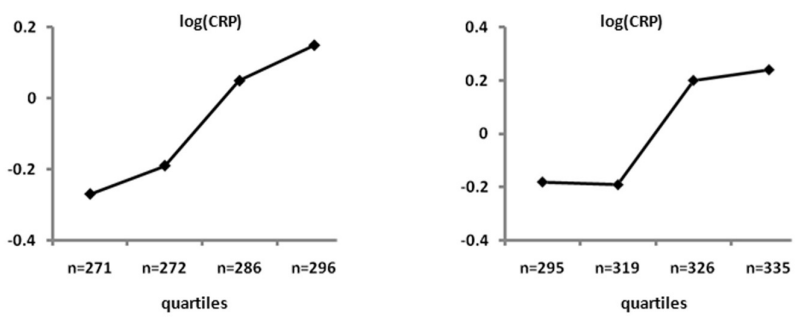

CRP and BMI
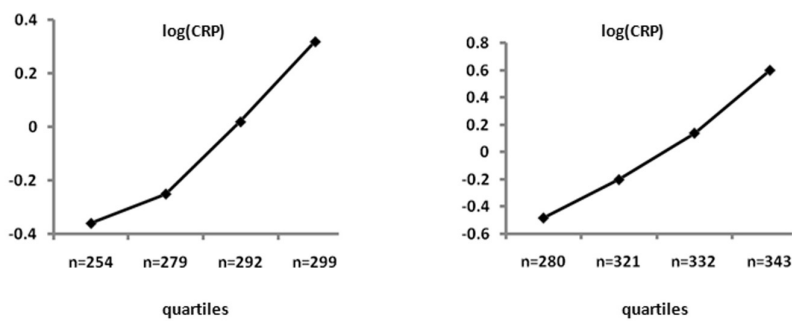

Fig. 1. Changes of hsCRP with age (quartiles) in men (left) and women (right). Data were obtained from analysis of $1 \%$ representative Czech population sample of age 25-34 years. CRP values were log-transformed for the use of statistical model to improve normality and to stabilize variants.

\section{CRP and depression}

A depressive mood is an independent behavioral risk of myocardial infarction in apparently healthy subjects (Koenig et al. 2006). This increase risk might be partly mediated by a proinflammatory status as it has been proven by a prospective study of Koenig et al. (2006) in the Augsburg MONICA. We have documented an increased proinflammatory status (measured by hsCR) in a large cohort of the Czech population (Pikhart et al. 2009) in individuals with a depression mood indicated by questionnaires. In this large group of analyzed individuals we were able to document that increased CRP in depressive individuals is completely independent on other variables related to CRP concentration. It can be concluded that a depressive mood is an independent factor of an increase of proinflammatory status and consequently it is probably the main reason of an increased risk of coronary heart disease in individuals with depression.

We tried to find if there is an increase in CRP concentration in depressive individuals also during acute MI. In a large group $(n=1374)$ of consecutive MI survivors in 5 coronary care units in Prague (Pitha et al. 2007), individuals with depression syndrome were identified. Their CRP concentration was determined after admission to coronary care units and 12 months later in control status. Although their basal CRP concentration differs from control population samples, the actual increase of CRP during acute coronary syndrome was not different from the rest of MI groups (without depression). It might be concluded that basal CRP concentration is probably regulated differently from an acute state myocardial infarction.

\section{Intervention of proinflammatory status}

As CRP concentration increases with increasing of body weight and is related to volume of visceral fat (Tintěra et al. 2004) we tried to influence this individual negative effect on atherosclerosis development in 40 young obese females (Dvořáková-Lorenzová et al. 2006). This group of very engaged young obese volunteers was recruited by advertisements in a life-style journal. They were intervened for 9 weeks by a combination of dietary counseling (directed to a decrease of high fat food consumption and moderate decrease of total energy intake) and an increase of physical exercise.

Weekly physical exercise consisted of three controlled 60-min sessions in a fitness-centre and two non-controlled (but registered) sessions of bicycling, brisk walking or jogging sessions over weekends. Total body weight dropped on average for more than $8 \mathrm{~kg}$ (7.7 \% of original body weight) with an adequate decrease of BMI, waist and hip circumference (Table 1). Although lipoprotein concentration did not change significantly (including triglycerides) there were highly significant changes in blood pressure, free fatty acids concentration and fasting insulin. In these young and healthy (with exception of overweight) volunteers LP concentration was within the normal range of the Czech women of the same age and no change of atherogenic lipoproteins was found after intervention but with significant increase of HDL concentration. The volume of visceral as well as subcutaneous fat decreased highly significantly (Table 1) but it is interesting the that the change of volume of visceral fat was almost twice as high as the change of subcutaneous one. In agreement with this change also CRP concentration decreased for $30 \%$ with a relatively high variation (Fig. 2). 

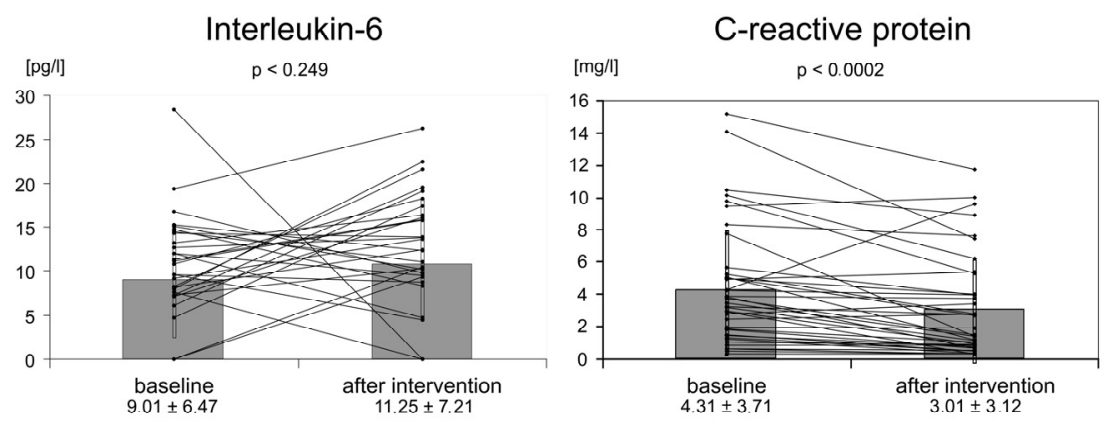

Fig. 2. Changes of hsCRP and Il-6 after intervention of 40 obese women by physical activity ( 9 weeks, 5 sessions/week). Mean \pm S.D. with individual changes comparing baseline and final intervention data.
Table 1. Effect of weight reduction of 40 young obese women by physical activity.

\begin{tabular}{lll}
\hline & Baseline & \multicolumn{1}{c}{$\begin{array}{c}\text { After } \\
\text { treatment }\end{array}$} \\
\hline Weight $(\mathrm{kg})$ & $88.56 \pm 12.51$ & $81.75 \pm 11.95 * * *$ \\
BMI $\left(\mathrm{kg} / \mathrm{m}^{2}\right)$ & $31.52 \pm 4.08$ & $29.09 \pm 3.89 * * *$ \\
Waist $(\mathrm{cm})$ & $93.24 \pm 10.32$ & $85.46 \pm 9.14 * * *$ \\
Hip $(\mathrm{cm})$ & $114.31 \pm 8.04$ & $106.30 \pm 7.76 * * *$ \\
W/H ratio & $0.82 \pm 0.06$ & $0.80 \pm 0.06$ \\
Glucose $(\mathrm{mmol} / \mathrm{l})$ & $5.21 \pm 0.43$ & $5.32 \pm 0.34$ \\
TC $(\mathrm{mmol} / \mathrm{l})$ & $5.26 \pm 0.82$ & $5.31 \pm 0.85$ \\
TG $(\mathrm{mmol} / \mathrm{l})$ & $1.20 \pm 0.50$ & $1.24 \pm 0.50$ \\
LDL-C $(\mathrm{mmol} / \mathrm{l})$ & $3.06 \pm 0.71$ & $3.01 \pm 0.74$ \\
HDL $-\mathrm{C}(\mathrm{mmol} / \mathrm{l})$ & $1.53 \pm 0.34$ & $1.62 \pm 0.39$ \\
HDL $/ \mathrm{TC}$ & $29.3 \pm 6.8$ & $31.1 \pm 9.7$ \\
Insulin $(\mu \mathrm{U} / \mathrm{l})$ & $10.1 \pm 2.4$ & $8.6 \pm 2.1 *$ \\
FFA $(\mu \mathrm{mol} / \mathrm{l})$ & $860 \pm 190$ & $570 \pm 130 * * *$ \\
SBP $(\mathrm{mm} \mathrm{Hg})$ & $127.53 \pm 8.98$ & $119.70 \pm 9.86 * * *$ \\
DBP $(\mathrm{mm} \mathrm{Hg})$ & $80.96 \pm 7.39$ & $73.69 \pm 7.66 * * *$ \\
\hline
\end{tabular}

Data are means \pm S.D. $(n=40)$. BMI - body mass index, W/H ratio - waist:hip ratio, TC - total cholesterol, TG - triglycerides, FFA - free fatty acids, SBP - systolic blood pressure, DBP diastolic blood pressure, Treatment effect: $* * * \quad p<0.001$, $* p<0.05$.

Although CRP concentration decreased in almost all individuals with high level of significance (Fig. 2) there was no change in interleukin-6 concentration when baseline and concentration after intervention were compared. We supposed that in this situation interleukin-6 production in macrophages is not playing a regulatory role in CRP production in the liver. It is very probable that this regulatory role is important in an acute phase as a result of acute infection or other type of damage. In this type of normal proinflammatory status induced by overweight, IL-6 is not playing any regulative role. Similarly to analysis of CRP relation to other risk factors of atherosclerosis in this intervention study, CRP concentration change is related to change of other risk factors of CVD. The decrease of body weight and adipose tissue volume was related not only to CRP decrease but also to change of blood pressure, FFA concentration and insulin sensitivity (Table 1).

When linear regression analysis of CRP concentration changes to relationship of other metabolic parameters was performed, the most important parameter was a change of concentration of fasting triglycerides. It might be supposed that triglyceride metabolism plays an important role in the induction of proinflammatory status. It can be hypothesized that CRP synthesis might be regulated by TG concentration in hepatocytes as there is a well known relationship of this parameter to VLDL triglyceride concentration. The high inflow of free fatty acids to hepatocytes producing certain accumulation of triglycerides within the cell might stimulate CRP synthesis as a result of proinflammatory status. Then it might be direct relationship of the size of adipose tissue and CRP concentration which is modified by total amount of released free fatty acids and total increment of triglycerides inside of hepatocytes. There is a possibility of more direct explanation of BMI relationship to CRP.

\section{Genetics of CRP concentration}

The documentation of heritability of CRP concentration was definitively presented in the large group of Norwegian monozygotic twins group of Kåre Berg (Retterstol et al. 2003) as within-pair correlation coefficient of CRP concentration was 0.40. This represents a confirmation of the family studies of Margaglione et al. (2000).

Results of a relation of individual CRP concentration changes to intravasal triglyceride concentration stimulated our research of a possible effect of polymorphisms of genes related to lipoprotein metabolism on proinflammatory status. Several candidate 
genes have been analyzed in a large representative population sample. Out of these genes the effect of polymorphism of apoprotein $\mathrm{C} 1$ and apoprotein $\mathrm{E}$ was proved (Tables 2 and 3 ).

Table 2. Effect of apoC1 gene polymorphism on CRP concentration.

\begin{tabular}{lllll}
\hline & $\begin{array}{l}\text { Genotype } \\
\text { Smoking }\end{array}$ & $\mathbf{1 / 1}$ & $\mathbf{1 / 2}$ & $\mathbf{2 / 2}$ \\
& & & \\
male & 0 & 1.59 & 1.26 & 1.01 \\
& & $1.41,1.72$ & $1.02,1.50$ & $0.45,1.52$ \\
& + & 2.04 & 1.79 & 1.32 \\
female & 0 & $1.76,2.32$ & $1.28,2.20$ & $0.82,1.73$ \\
& & 1.91 & 1.84 & 1.29 \\
& + & $1.74,2.08$ & $1.58,2.01$ & $0.59,1.79$ \\
& & 1.94 & 1.75 & 2.18 \\
& & $1.59,2.30$ & $1.15,2.14$ & $0,6.23$ \\
\hline
\end{tabular}

Mean of CRP stratified by sex with $95 \%$ confidence limits. Data were obtained after analysis of $1 \%$ representative Czech population sample, 1127 male and 1278 female subjects.

Table 3. Effect of apoE gene polymorphism on CRP concentration.

\begin{tabular}{|c|c|c|c|c|}
\hline & $\begin{array}{c}\text { Genotype } \\
\text { Smoking }\end{array}$ & E2/3 & E3/3 & E3/4 \\
\hline \multirow[t]{4}{*}{ male } & 0 & 1.78 & 1.54 & 1.25 \\
\hline & & $1.34,2.22$ & $1.37,1.71$ & $0.92,1.58$ \\
\hline & + & 2.19 & 1.93 & 1.66 \\
\hline & & $1.27,3.11$ & $1.67,2.20$ & $1.07,2.26$ \\
\hline \multirow[t]{4}{*}{ female } & 0 & 1.83 & 1.90 & 1.67 \\
\hline & & $1.45,2.20$ & $1.73,2.06$ & $1.33,2.02$ \\
\hline & + & 2.16 & 1.85 & 1.88 \\
\hline & & $1.34,2.98$ & $1.50,2.21$ & $0.91,1.92$ \\
\hline
\end{tabular}

Mean of CRP stratified by sex with $95 \%$ confidence limits. Data were obtained after analysis of $1 \%$ representative Czech population sample, 1127 male and 1278 female subjects.

The effect of apoC1 polymorphism was significant both in non-smokers (with lower CRP concentration) and smokers (with higher CRP concentration). The trend of decreasing of CRP concentration from $1 / 1$ homozygotes through heterozygotes $1 / 2$ to $2 / 2$ homozygotes reached statistical significance. The effect of apoprotein E polymorphism was less manifested when groups of individuals with genotype E2/3, E3/3 and E3/4 were compared. This effect was manifested only in men and not in women. Analysis of effect of these two genes on CRP was performed with application of statistical model including standardization for age and body weight.

A more direct genetic effect of proinflammatory status was found in a study of families of probands with documented coronary atherosclerosis under age 65. This study was completed at the Regional Hospital in South Bohemia with the hypothesis that an increase of CRP in spouses with probands would document an environmental effect (family hygiene) whereas an increase in adult offspring would represent a possible genetic effect.200 probands were enrolled to the study as consecutive patients with coronarography proved atherosclerosis of coronary tree admitted to cardiosurgery for coronary reconstruction. All family members (spouse and children - response rate varied between $75-97 \%$ in different groups) were invited to outpatient clinic to physical and biochemical check. Data of probands, their spouses, sons and daughters were compared to sex- and age-matched controls from the $1 \%$ representative sample of the Czech population (Table 4).

Although $22 \%$ of probands were already on statin therapy which has been proved to decrease CRP concentration, still their CRP was for $60 \%$ higher compared to control groups. This difference was not influenced by age difference (age-matched) neither by difference of body weight as it was similar to control group. Concentration of CRP in spouses was not different from controls documenting no effect of family environment on proinflammatory status. A highly significant decrease of HDL cholesterol concentration in patients was found in comparison with controls. A lower concentration of LDL cholesterol in patients is produced predominantly by frequent statin treatment. On the other hand, we might expect also an effect of preventive influence of diet as these patients were already treated by their cardiologist long before admission to cardiosurgery. This opinion is supported also by decrease of LDL cholesterol of their spouses compared to controls.

There were no differences in BMI, total cholesterol and HDL cholesterol concentration when sons and daughters of probands were compared to controls (Table 4). They elicited only an increase in concentration of triglycerides but only in daughters and not in sons. A highly significant increase of CRP concentration was found in male offspring of probands (almost as twice as high) whereas this increase was less pronounced (but still significant) in their daughters (Table 4). It can be 
Table 4. Characteristics of the offspring of myocardial infarction survivors compared to age-matched controls.

\begin{tabular}{lllllll}
\hline & Males & Controls & p & Females & Controls & p \\
\hline$n$ & 106 & 100 & & 86 & 100 \\
Age $($ years $)$ & $30.04 \pm 6.60$ & $29.60 \pm 1.61$ & $\mathrm{~ns}$ & $29.56 \pm 6.58$ & $28.80 \pm 1.26$ & $\mathrm{~ns}$ \\
BMI $\left(\mathrm{kg} / \mathrm{m}^{2}\right)$ & $26.13 \pm 3.70$ & $26.49 \pm 3.48$ & $\mathrm{~ns}$ & $23.67 \pm 4.15$ & $23.67 \pm 4.14$ & $\mathrm{~ns}$ \\
$T C(\mathrm{mmol} / \mathrm{l})$ & $5.40 \pm 1.04$ & $5.20 \pm 0.91$ & $\mathrm{~ns}$ & $5.08 \pm 0.98$ & $4.89 \pm 1.07$ & $\mathrm{~ns}$ \\
$T G(\mathrm{mmol} / \mathrm{l})$ & $2.21 \pm 1.90$ & $1.52 \pm 0.87$ & $* *$ & $1.43 \pm 0.87$ & $1.05 \pm 0.61$ & $* *$ \\
$L D L-C(\mathrm{mmol} / \mathrm{l})$ & $3.12 \pm 0.87$ & $3.25 \pm 0.81$ & $\mathrm{~ns}$ & $2.83 \pm 0.82$ & $2.85 \pm 0.91$ & $\mathrm{~ns}$ \\
$H D L-C(\mathrm{mmol} / \mathrm{l})$ & $1.26 \pm 0.31$ & $1.27 \pm 0.36$ & $\mathrm{~ns}$ & $1.48 \pm 0.37$ & $1.57 \pm 0.36$ & $\mathrm{~ns}$ \\
$H s C R P(\mathrm{mg} / \mathrm{l})$ & $1.42 \pm 1.70$ & $0.75 \pm 0.83$ & $* *$ & $2.18 \pm 2.46$ & $1.38 \pm 1.67$ & $*$ \\
\hline
\end{tabular}

Data are means \pm S.D. TC, LDL-C, HDL-C represent total cholesterol concentration and its fractions in LDL and HDL. TG represents triglycerides. Differences from respective controls: $* * p<0.01, * p<0.05$.

concluded that proinflammatory status is at minimum partly inherited, as offspring of individuals with documented coronary artery sclerosis and proinflammatory status display higher CRP concentration analyzed in age around 35-40 years much earlier before clinical complications generally appeared.

Proinflammatory status is supposed one of the most important risk of premature atherosclerosis and CRP concentration has been proved as the most reliable marker of this status (Danesh et al. 2004). It is very improbable that CRP molecule might be atherogenic per $s e$. It is a marker of individually determined properties of monocytes to be trapped with arterial wall during process of scavenging of an excess of LDL particles in the subendothelial space. Quite significant correlation of CRP concentration with several traditional risk factors of atherosclerosis makes application of this parameter for a determination of individual risk of premature clinical complication of atherosclerosis very complicated (Welsh et al. 2008).

\section{Conflict of Interest}

There is no conflict of interest.

\section{Acknowledgements}

The study was supported by MSMT Project 1M0510.

\section{References}

BROWN MS, GOLDSTEIN JL: A receptor mediated-pathway for cholesterol homeostasis. Nature 232: 34-47, 1986.

CASTELLI WP, GARRISON RJ, WILSON PWF, ABBOTT RD, KALOUSDIAN S, KANNEL WB: Incidence of coronary heart disease and lipoprotein cholesterol levels. JAMA 256: 2835-2835, 1986.

DANESH J, WHEELER JG, HIRSCHFELD GM, SHINICHI E, EIRIKSDOTTIR G, RUMLEY A, LOWE GDO, PEPYS MD, GUDNASSON V: C-reactive protein and other circulating markers of inflammation in the prediction of coronary heart disease. N Engl J Med 350: 1387-1397, 2004.

DVOŘÁKOVÁ A, POLEDNE R: High-sensitivity C-reactive protein - new parameter in cardiovascular risk assessment. Vnitř Lék 50: 852-857, 2004.

DVOŘÁKOVÁ-LORENZOVÁ A, SUCHÁNEK P, HAVEL PJ, STÁVEK P, KARASOVÁ L, VALENTA Z, TINTĚRA J, POLEDNE R: The decrease in C-reactive protein concentration after diet and physical activity induced weight reduction is associated with changes in plasma lipids, but not interleukin-6 or adiponectin. Metabolism 55: 359-365, 2006.

FESTA A, D'AGOSTINO R JR, HOWARD G, MYKKÄNEN L, TRACY RP, HAFFNER SM: Chronic subclinical inflammation as part of the insulin resistance syndrome: the Insulin Resistance Atherosclerosis Study (IRAS). Circulation 102: 42-47, 2000.

JONASSON L, HOLM J, SKALLI O, BONDJERS G, HANSSON GK: Regional accumulations of T cells, macrophages, and smooth muscle cells in the human atherosclerotic plaque. Arteriosclerosis 6: 131-138, 1986.

KEYS A: Human atherosclerosis and the diet. Circulation 5: 115-118, 1952. 
KEYS A: Coronary heart disease in seven countries. Nutrition 13: 250-252, 1970.

KOENIG W, KHUSEYINOVA N, BAUMERT J, THORAND B, LOEWEL H, CHAMBLESS L, MEISINGER C, SCHNEIDER A, MARTIN S, KOLB H, HERDER C: Increased concentrations of C-reactive protein and IL-6 but not IL-8 are independently associated with incident coronary events in middle-aged men and women. Results from the MONICA/KORA Augsburg Case-Cohort Study, 1984-2002. Arterioscler Thromb Vasc Biol 26: 2745-2751, 2006.

MARGAGLIONE M, CAPPUCCI G, COLAIZZO D, VECCHIONE G, GRANDONE E, Di MINNO G: C-reactive protein in offspring is associated with the occurrence of myocardial infarction in first-degree relatives. Arterioscler Thromb Vasc Biol 20: 198-203, 2000.

MENDALL MA, PATEL P, BALLAM L, STRACHAN D, NORTHFIELD TC: C-reactive protein and its relation to cardiovascular risk factors: a population based cross-sectional study. BMJ 312: 1061-1065, 1996.

PIKHART H, HUBÁČEK JA, KUBÍNOVÁ R, NICHOLSON A, PEASEY A, ČAPKOVÁ N, POLEDNE R, BOBAK M: Depressive symptoms and levels of C-reactive protein: a population-based study. Soc Psychiatry Psychiatr Epidemiol 44: 217-222, 2009.

PIŤHA J, HUBÁČEK JA, POLEDNE R, STANĚK V, ASCHERMANN M, GEBAUEROVÁ M, HÁJEK P, NIEDERLE P, PĚNIČKA M, VESELKA J: Genetic determination the prognosis in survivors of acute coronary syndromes. Study design and rationale for a multicenter study. Cor Vasa 49: 134-137, 2007.

RETTERSTOL L, EIKVAR L, BERG K: A twin study of C-reactive protein compared to other risk factors for coronary heart disease. Atherosclerosis 169: 279-282, 2003.

RIDKER PM, CUSHMAN M, STAMPFER MJ, TRACY RP, HENNEKENS CH: Inflammation, aspirin, and the risk of cardiovascular disease in apparently healthy men. $N$ Engl J Med 336: 973-979, 1997.

RIDKER PM, CUSHMAN M, STAMPFER MJ, TRACY RP, HENNEKENS CH: Plasma concentration of C-reactive protein and risk of developing peripheral vascular disease. Circulation 97: 425-428, 1998.

RIDKER PM, RIFAI N, PFEFFER MA, SACKS F, BRAUNWALD E: Long-term effect of pravastatin on plasma concentration of C-reactive protein. The cholesterol and recurrent events (CARE) investigators. Circulation 100: 230-235, 1999a.

RIDKER PM, KUNDSIN RB, STAMPFER MJ, STAMPFER MJ, POULIN S, HENNEKENS CH: Prospective study of Chlamydia pneumoniae IgG seropositivity and risk of future myocardial infarction. Circulation 99: 11611164, 1999b.

RIDKER PM, FONSECA FA, GENEST J, GOTTO AM JR, KASTELEIN JJ, KOENIG W, LIBBY P, LORENZATTI AJ, NORDESTGAARD BG, SHEPHERD J, WILLERSON JT, RIDKER PM, DANIELSON E, GLYNN RJ, JUPITER STUDY GROUP. Rosuvastatin to prevent vascular events in men and women with elevated C-reactive protein. N Engl J Med 359: 2195-2207, 2008.

ROSS R: Atherosclerosis: an inflammatory disease. N Engl J Med 340: 115-118, 1999.

SAIKKU P, MATTILA M, NIEMINEN S, HUTTUNEN JK, LEINONEN M, EKMAN MR, MÄKELÄ PH, VALTONEN V: Serological evidence of an association of a novel Chlamydia, TWAR, with chronic coronary heart disease and acute myocardial infarction. Lancet 2: 983-986, 1988.

SPRINGER TA, CYBULSKY MI: Traffic signals on endothelium for leukocytes in health, inflammation, and atherosclerosis. In: Atherosclerosis and Coronary Artery Diseases. FUSTER V, ROSS R, TOPOL EJ (eds), Lippincott-Raven, Philadelphia, 1996, pp 511-538.

STEHBENS WE: Anitschkow and the cholesterol over-fed rabbit. Cardiovasc Pathol 8: 177-178, 1999.

TINTĚRA J, HARANTOVÁ P, SUCHÁNEK P, DVOŘÁKOVÁ A, ADAMOVÁ M, HÁJEK M, POLEDNE R: Quantification of intra-abdominal fat during controlled weight reduction: assessment using the watersuppressed breath-hold MRI technique. Physiol Res 53: 229-234, 2004.

VAN DER WAL AC, DAS PK, BENTZ VAN DE BERG D, VAN DER LOOS CM, BECKER AE: Atherosclerotic lesions in humans: in situ immunophenotypic analysis suggesting an immune mediated response. Lab Invest 61: 166$170,1989$.

WELSH P, PACKARD JC, SATTAR N: Novel antecedent plasma biomarkers of cardiovascular disease: improved evaluation methods and comparator benchmarks raise the bar. Curr Opin Lipidol 19: 563-571, 2008. 
YUDKIN JS, STEHOUWER CD, EMEIS JJ, COPPACK SW: C-reactive protein in healthy subjects: associations with obesity, insulin resistance and endothelial dysfunction: a potential role for cytokines originating from adipose tissue? Arterioscler Thromb Vasc Biol 19: 972-978, 1999. 